\title{
Por um dicionário bilíngue pedagógico para a leitura em língua estrangeira
}

\section{For a pedagogical bilingual dictionary for reading comprehension in a foreign language}

\section{Sandra Dias Loguercio*}

Resumo: Este trabalho reflete sobre a natureza da informação lexicográfica dos dicionários bilíngues e seu uso para atividades de leitura-compreensão por um público não proficiente na língua de recepção, propondo, a partir daí, um dicionário bilíngue pedagógico para a leitura em língua estrangeira. Por se tratar de leitores cuja experiência de estudo dessa língua é bastante limitada, exigindo de sua parte uma autonomia precoce de aprendizagem, esse dicionário deve reunir as funções comunicativa, fornecendo a informação buscada na situação de leitura, e cognitiva, favorecendo a aprendizagem de saberes lexicais e gramaticais que incidam na competência leitora. Para isso, é proposta uma reformulação de sua microestrutura que passa pelo tratamento da unidade lexical, do modo de criação referencial, contextual e por uma organização hipertextual, elementos ilustrados aqui através do par de línguas francês-português.

Palavras-chave: Dicionário bilíngue; lexicografia bilíngue pedagógica; leituracompreensão; função comunicativa; função cognitiva.

Abstract: This work reflects on the nature of lexicographical information of bilingual dictionaries and their use for reading comprehension activities by a public which is not proficient in the target language. Thus, a pedagogical bilingual dictionary for reading in a foreign language is proposed. Once these readers have a very limited

\footnotetext{
* Departamento de Línguas Modernas, Instituto de Letras, Universidade Federal do Rio Grande do Sul. E-mail: sandraloguercio@hotmail.com
} 
LOGUERCIO, S. D. - Por um dicionário bilíngue pedagógico para a leitura em língua estrangeira

experience of studying this language and are supposed to have an early autonomy of learning, this dictionary must comprehend communicative and cognitive functions. Communicative functions should provide some information sought in the reading situation, while cognitive functions should encourage the learning process of lexical and grammatical knowledge that cover reading competence. For this reason, a reformulation of its microstructure is proposed, which includes the treatment of the lexical unit, referential and contextual productions, and hypertextual organization. These elements are illustrated here through the language pair French-Portuguese.

Keywords: bilingual dictionary; pedagogical bilingual lexicography; reading comprehension; communicative function; cognitive function.

\section{Introdução}

Os dicionários, de modo geral, sempre estiveram associados à consulta visando elucidar o sentido das palavras e, portanto, sempre foram empregados para, entre outros fins, a compreensão de textos. Aliás, essa função aparece já na origem da lexicografia ocidental, oriunda das glosas feitas em idioma vernacular para auxiliar os povos europeus na Idade Média a compreenderem textos escritos em latim. Não obstante, como observa Béjoint (2005: 12), mesmo que "o dicionário seja acima de tudo um instrumento para a compreensão, [...] restrições de diversas ordens pesavam até o presente sobre o dicionário tradicional e dificultavam a realização de tal tarefa”. ${ }^{1}$

Essa situação está relacionada com o próprio projeto inicial da lexicografia, qual seja: reunir elementos capazes de explicar o sentido das palavras (unidade gráfica de fácil apreensão) e organizá-las em ordem alfabética a fim de construir um instrumento de compreensão independente dos textos e do contexto situacional. O dicionário se afasta assim da tarefa

\footnotetext{
${ }^{1}$ Todas as citações deste artigo escritas originalmente em outra língua foram traduzidas pela autora.
} 
LOGUERCIO, S. D. - Por um dicionário bilíngue pedagógico para a leitura em língua estrangeira

das glosas, aquela de explicar um discurso para tratar, sobretudo, do sistema, da língua. Isso cria a possibilidade de responder a outros objetivos, tais como o de informar sobre os significados das palavras ou sobre os equivalentes em uma outra língua, e traz, ao mesmo tempo, outros desafios. Diferentemente das glosas, recursos discursivos atreladas ao texto e, assim, direcionadas especificamente a um leitor-alvo e a uma situação de leitura específica, os verbetes dicionarísticos são oriundos de abstrações que configuram um texto particular que deve ser capaz de responder a diferentes situações de consulta.

\section{Um dicionário bilíngue para a leitura- compreensão: por que e para quem?}

\subsection{A visão do professor vs a visão do aprendiz}

Apesar de tudo, como revelam inúmeras pesquisas (ver BÉJOINT 1981, 2003; BogAaRdS 1988, 1995; Welker 2005, 2006), os dicionários de modo geral são usados principalmente durante atividades de leitura e a informação mais buscada é o significado das palavras. Sua vocação continua sendo de certa forma, portanto, informar sobre o "sentido". A esse dado, outros devem ser considerados, como, por exemplo, o fato de que o DB é o mais usado por aprendizes de uma língua estrangeira (LE), sobretudo para a compreensão escrita e principalmente nos primeiros anos de aprendizagem. Em compensação, ele é o tipo de dicionário mais criticado pelos usuários e menos indicado pelos professores (WELKER 2006). Esse conflito se torna bastante evidente nas aulas de leitura-compreensão em LE, como nos chamados “instrumentais” difundidos na América Latina. 
LOGUERCIO, S. D. - Por um dicionário bilíngue pedagógico para a leitura em língua estrangeira

Quando se trata de compreensão escrita, por um lado, professores buscam refrear o uso do dicionário. Eles sabem que a atividade de leitura vai muito além da decodificação do texto e que o processo de inferência dos conteúdos desempenha um papel primordial na construção de uma competência leitora. Ou então eles sugerem a consulta de dicionários monolíngues, aqueles que tradicionalmente dão conta do significado das palavras e apresentam uma descrição linguística do léxico, propícia portanto à aprendizagem. Além de serem normalmente mais completos, busca-se garantir assim que o aprendiz não "traduza" o que está lendo. Em último caso, recomendam o dicionário semibilíngue, comumente chamado de learner's dictionary, que traz uma definição breve na LE e um equivalente na língua do consulente. Essa última opção vem satisfazer, teoricamente, a orientação do professor e a necessidade do aprendiz e constitui, sem dúvida, um marco da lexicografia pedagógica. No entanto, na prática, se o consulente não apresenta um certo nível de proficiência linguística na LE a fim de tirar proveito de tal combinação, ou seja, compreender a definição na língua de partida, ele acaba lendo apenas o equivalente proposto, tal como faria com um DB.

Por outro lado, aprendizes iniciantes na LE em situação de leitura não conseguem dispensar o DB (seja impresso ou informatizado), o que está longe de ser um capricho. Como nos revela a prática em cursos de Francês Instrumental $^{2}(\mathrm{FI})$, a consulta ao DB faz parte de suas estratégias de leitura, compreendidas, nesse caso, como o que eles fazem para ler. Ora, pesquisas cognitivas sobre processos de leitura e trabalhos que investigam o papel do léxico na atividade de compreensão escrita mostram-nos que o leitor só consegue tirar proveito de fato dos elementos contextuais e situacionais para interpretar globalmente um texto se ele tem um domínio elementar e automatizado dos elementos linguísticos (gramática e léxico) (Gaonac’h et

\footnotetext{
${ }^{2}$ Ver a pesquisa-piloto publicada em Loguercio, 2007, e as duas pesquisas empíricas que compõem a tese que deu origem a este artigo, Loguercio, 2013.
} 
LOGUERCIO, S. D. - Por um dicionário bilíngue pedagógico para a leitura em língua estrangeira

al., 1996) ou, caso contrário, se ele procede de maneira mais refletida e analítica diante de palavras desconhecidas (PIETRARóIA 1997; CARRASCO e MASPERI 2004). O texto que se torna um conjunto de "adivinhações" para o leitor está longe de diverti-lo, podendo não somente desmotivá-lo como "enganá-lo" enormemente. 0 processo de decodificação, menosprezado em grande medida pela didática das $L E$, integra na verdade todo processo de interpretação ou, melhor, de "interação" entre leitor e texto. A esse respeito, vale lembrar que:

O aluno deve dar vida ao que, no sentido literal da palavra, está em estado de letra morta. Deve, por uma atividade própria, produzir sentido com um interlocutor mudo, que não confirma nem refuta, que não julga nem avalia as hipóteses que o leitor faz explícita ou implicitamente para dar sentido ao que lê. Esse interlocutor se apresenta como um conjunto de formas morfológicas, sintáticas, lexicais articuladas entre si. (LAHIRE 2008: 89)

Consequentemente, para o aprendiz-leitor, tal como o aluno de $\mathrm{FI}$, não é que o DB responda melhor a suas expectativas e necessidades de compreensão, mas é que esse tipo de dicionário é visto muitas vezes como o único recurso de apoio a suas dificuldades de leitura. É o instrumento que, em última instância, faz o elo entre a "língua da informação", aquela na qual são veiculados os escritos, e a "língua da representação", ${ }^{3}$ aquela na qual elabora a representação do escrito e na qual se apoia naturalmente para ler. Em vez de impor este ou aquele procedimento diante dos textos, recomendar este ou aquele dicionário para o aluno, cabe então se questionar, antes de tudo, sobre a natureza dessa aprendizagem em LE, explicitamente parcial, que passa por uma autonomização precoce por parte do aprendiz.

\footnotetext{
${ }^{3}$ Noções usadas em metodologias de intercompreensão (cf. Tyvaert, 2008). 
LOGUERCIO, S. D. - Por um dicionário bilíngue pedagógico para a leitura em língua estrangeira

\subsection{Algumas considerações sobre o aprendiz-leitor de LE}

Em primeiro lugar, é justamente por se tratar de um público que tende a ter uma experiência de ensino bastante restrita da LE que ele precisa de instrumentos que possam responder a certas lacunas durante seu percurso de aprendizagem e durante suas leituras. Na verdade, as próprias condições dessa prática de ensino levam os alunos a se tornarem autônomos mais rapidamente da mediação do professor. Tal aprendizagem só terá, consequentemente, efeitos positivos a longo prazo se o aprendiz puder dar continuidade a seus estudos linguísticos. Isso passa, entre outros, por situações de consulta sobre a língua em questão motivadas não apenas por uma falta de vocabulário, mas por uma necessidade de aprendizagem mais profunda sobre seu funcionamento linguístico e discursivo.

Em segundo lugar, os instrumentos pedagógicos que acompanham os aprendizes ao longo de suas atividades e da aprendizagem das línguas, como os dicionários, não podem ser úteis a todos os públicos ao mesmo tempo, nem em todas as situações de consulta. Suas necessidades de informação se distinguem essencialmente pela atividade comunicativa empreendida, aquela que os motiva a consultar o dicionário, e por seu nível de competência linguística. Desse modo, dicionários que podem ser eficazes em determinados contextos de ensino-aprendizagem não servirão a outros. Não haveria razão, aliás, em falar de didática nem de lexicografia pedagógica se não levássemos em conta essas variáveis.

Por fim, se os DBs podem em certos casos ajudar na tarefa de compreender um texto em LE, sua eficácia para boa parte dos aprendizes, principalmente para iniciantes, tende a ser mais fortuita do que previsível. Marcados, cada vez mais, por diferenças oriundas de projetos distintos, o que ainda os torna semelhantes, a saber, o fato de relacionarem uma unidade 
LOGUERCIO, S. D. - Por um dicionário bilíngue pedagógico para a leitura em língua estrangeira

lexical com seus possíveis equivalentes em uma outra língua, não garante finalmente sua eficácia para a compreensão. Com efeito, a questão à qual eles buscam responder é "como se traduz uma dada palavra?" e não "o que se compreende por essa palavra?", o que constitui uma diferença de princípio considerável. Não é por acaso que alguns teóricos da área consideram em suas tipologias a concepção de um dicionário destinado especificamente à leitura em LE (como, Duda et al. 1986 apud Carvalho 2001; Hausmann 2002; BÉJoInt 2003; WeLKER 2008), distinguindo-o, entre outros, do dicionário para a expressão em LE e do dicionário para a tradução.

Nesse sentido, vale salientar ainda as infinitas possibilidades de coleta e oferecimento de dados permitidas atualmente pelas novas tecnologias e pela web. Estas vêm, entre outros aspectos, aumentar a capacidade de armazenamento de informação (tornando o dicionário multifuncional, por exemplo), tornar flexível a consulta (na medida em que o consulente passa a poder escolher a via de acesso aos dados) e integrar a consulta à atividade de leitura através do recurso do hipertexto, reduzindo a distância entre usuário e instrumento lexicográfico. ${ }^{5}$ Esse atual instrumento, que compete ainda com os tradicionais DBs impressos, consiste, na verdade, em um motor de busca com acesso a um banco de dados e/ou a outras fontes disponibilizadas na web. Mas se, por um lado, esses recursos revolucionam de fato a prática lexicográfica, por outro, eles só representam um ganho de qualidade se os dados que oferecem forem suficientemente ricos e precisos quanto a suas análises lexicais. Duas condições que estão, na realidade, intimimante relacionadas com as expectativas do consulente considerado e com as situações que motivam suas consultas.

\footnotetext{
${ }^{4}$ Ver, entre outros, Alvar Ezquerra (1981) e Marello (1996).

${ }^{5}$ Ver, por exemplo, o software Alexandria desenvolvido pela sociedade francesa Mémodata e que integra o dicionário Sensagent, e a Base lexicale du français (BLF), desenvolvida pelo Grupo de Pesquisa em Lexicografia Pedagógica (GRELEP) da Universidade Católica de Leuven (cf. Binon e Verlinde, 2008).
} 
LOGUERCIO, S. D. - Por um dicionário bilíngue pedagógico para a leitura em língua estrangeira

O aprendiz-leitor do qual tratamos não está preocupado em ler para aprender a língua, mas antes em aprender (minimamente) a língua para ler (e aprender outras coisas). Suas preferências lexicográficas estão diretamente relacionadas com as informações que, de seu ponto de vista, facilitam sua leitura, não necessariamente sua aprendizagem. ${ }^{6}$

Sabemos, porém, que são justamente os momentos de questionamento sobre a língua durante a leitura que criam novas oportunidades de aprendizagem para esses sujeitos. No caso específico dos alunos de FI que não têm um conhecimento elementar da gramática da LE, parece natural que as perguntas sejam feitas à "palavra" - porta de entrada para a compreensão da língua escrita e, nesse caso, para a reflexão gramatical - e que esses momentos sejam marcados prioritariamente pela consulta ao DB. É nesse âmbito que propomos apresentar algumas reflexões teórico-metodológicas para a elaboração de um instrumento lexicográfico destinado à leituracompreensão.

\section{Da aquisição do léxico e da lexicografia} pedagógica

\subsection{Breves considerações sobre o papel do léxico na aprendizagem em língua estrangeira}

Podemos dizer sumariamente que a aquisição de línguas se dá por uma espécie de hierarquia e de modo acumulativo, sendo que a língua primeira (ou a mais imponente, presente) tende a desempenhar um papel de mediação

\footnotetext{
${ }^{6} 0$ que parece justificar a diferença de pontos de vista mencionada anteriormente entre professores e aprendizes.
} 
LOGUERCIO, S. D. - Por um dicionário bilíngue pedagógico para a leitura em língua estrangeira

inicialmente entre uma língua segunda e o sentido, assim como outras línguas adquiridas podem desempenhar igualmente esse mesmo papel conforme a experiência do sujeito. Como lembram Griggs et al. (2002), esse processo implica dois tipos de saberes: um saber procedural, da ordem do saber-fazer, já que se trata de saber se comunicar em uma língua, portanto de agir, e um saber declarativo, aquele que pode ser expresso a partir da tomada de consciência do que foi aprendido. 0 saber declarativo reforça e alimenta a base para o saber procedural, enquanto este último força o sujeito a reinterpretar, a corrigir e a reconstruir os dados assimilados, ou seja, o saber declarativo. É nesse jogo entre o agir (a comunicação) e o refletir (a tomada de consciência) que se encontra o elo entre o cognitivo e o social. 0 léxico desempenha um papel nesses dois planos: é pelas unidades lexicais que temos acesso ao léxico mental ${ }^{7}$ (o plano cognitivo), assim como é principalmente o léxico que desencadeia a comunicação verbal (o plano social).

Os didáticos das línguas insistem, desse modo, na importância do trabalho reflexivo para a apreensão do aspecto lexical. Encontramos esse ponto de vista, entre outros, em: Galisson $(1979,1983)$, que propõe pistas através do que chama de "lexicometodologia", isto é, uma transposição didática da lexicologia aos aprendizes, e lança o desafio aos lexicógrafos da "lexicultura", ou seja, o acesso à cultura através do estudo do léxico; e em Graves (1987 apud BoGAARDS 1994), que destaca os elementos essenciais para o enriquecimento lexical, como a exploração de materiais diversos, a instrução acerca dos recursos disponíveis para essa exploração e a ampliação do conhecimento metalinguístico.

Quanto à atividade de leitura especificamente, esse ponto de vista é defendido também por: Pietraróia (1997), para quem é importante

\footnotetext{
${ }^{7}$ Metáfora criada pelos psicolinguistas para tratar do "sistema de representações lexicais locais" que é assimilado pela nossa memória semântica (ou memória de longo prazo). Esse sistema é constituído por elementos - ortográficos, fonológicos, semânticos, sintáticos, etc. que representam a soma dos conhecimentos que o sujeito interiorizou acerca das palavras de sua língua (cf. Spinelli \& Ferrand, 2005), e mais adiante de outras.
} 
LOGUERCIO, S. D. - Por um dicionário bilíngue pedagógico para a leitura em língua estrangeira

desenvolver um trabalho de leitura de modo metalinguístico, não automatizado, ou seja, sem desprezar as palavras desconhecidas; e Carrasco e Masperi (2004) que, no âmbito dos trabalhos voltados à metodologia de intercompreensão, propõem atividades que visam explorar as raízes comuns das línguas e suas semelhanças. ${ }^{8}$

Esses autores compartilham da ideia de que é preciso, em suma, desenvolver uma atitude investigativa nos aprendizes relativa ao léxico. Cabe ao professor, porém, apresentar-lhes as ferramentas para que possam fazer com que sua aquisição progrida e para que enfrentem suas dificuldades de modo mais autônomo. Nesse sentido, vale salientar que o dicionário, ou qualquer outro suporte pedagógico que acompanhe os aprendizes, não será bem empregado se, em um dado momento, não for ele mesmo objeto de ensino e de reflexão durante a aprendizagem. Em última análise, não basta apenas elaborar e indicar boas obras de referência: é preciso também levar o aprendiz a integrá-las a suas práticas de estudo.

A consulta ao dicionário, como nos lembra Tarp (2008, 2009), não teria uma incidência direta sobre o desenvolvimento do desempenho linguísticocomunicativo, mas indireta. Ao integrar as estratégias de comunicação - tanto de expressão quanto de recepção - durante a aprendizagem, a consulta a obras dicionarísticas pode contribuir em dois níveis distintos: no nível dos saberes (para o qual desempenha uma função cognitiva), já que o dicionário reúne saberes sobre o léxico e a gramática de uma ou mais línguas, e no nível das informações (função comunicativa), já que facilita o acesso a informações pontuais que podem ajudar o aprendiz em uma situação de comunicação. Vale notar assim que o "melhor" dicionário - ou o mais "pedagógico" - não é necessariamente aquele que facilita a atividade de expressão" mas aquele

\footnotetext{
${ }^{8}$ Para um panorama atual dessas pesquisas, ver Conti e Grin (2008).

9 Na literatura sobre lexicografia pedagógica voltada às LEs, a noção de "aprendizagem linguística" aparece comumente vinculada à de competência de expressão.
} 
LOGUERCIO, S. D. - Por um dicionário bilíngue pedagógico para a leitura em língua estrangeira

mais adequado às particularidades do consulente, tanto no tocante a seu nível de aprendizagem quanto no tocante a seus objetivos de aprendizagem.

\subsection{A lexicografia pedagógica a serviço do aprendiz- leitor}

A distinção entre situação de leitura e situação de aprendizagem que parece estar no cerne da reflexão feita até aqui sobre o papel do léxico e nos próprios cursos de $\mathrm{Fl}$, quando distinguimos a perspectiva do aprendiz daquela do professor, reflete-se igualmente nos estudos em lexicografia. Ela está relacionada ao público-alvo e à sua relação com a LE, o que marca, com razão, pontos de vista e projetos distintos. Curiosamente, porém, ao se considerar um público principiante na LE, o enfoque é o auxílio à leitura, ao passo que, ao se considerar um público de aprendizes de um nível avançado, o enfoque é a aprendizagem. Seria possível reunir, no entanto, as duas funções em um único instrumento quando se trata de um aprendiz que tem certa pressa em se tornar um leitor na LE? As reflexões apresentadas a seguir nos ajudam a circunscrever tal projeto.

Para Béjoint (2003), que propõe princípios para o que ele chama de "dicionário de mediação", este se distinguiria de um DB convencional principalmente por restituir no idioma do leitor o sentido dos elementos lexicais de uma LE que são, em certa medida, apagados na relação de equivalência interlinguística. Para esse autor, o consulente que não domina suficientemente bem a LE precisa de um "elucidador" adaptado à sua competência linguística e cultural. Esse elucidador, que pode corresponder a um equivalente em alguns casos, também pode vir na forma de uma definição breve em língua materna (LM), de um exemplo ou mesmo de uma imagem servindo, sobretudo, de auxílio à resolução de uma dúvida precisa de incompreensão lexical. Em suma, o que Béjoint propõe é uma adaptação da 
LOGUERCIO, S. D. - Por um dicionário bilíngue pedagógico para a leitura em língua estrangeira

metalinguagem do DB que deveria, além disso, ser reduzido aos dados essenciais para a leitura e não ter qualquer preocupação com a aprendizagem.

Voltado, por sua vez, a um público de estudantes avançados em FLE, Hausmann (2002) reflete sobre o que seria um DB destinado à aprendizagem de um "vocabulário passivo", isto é, útil para a leitura. Na contramão dos projetos de intercompreensão, ele defende a ideia de que, nesse caso, é o critério da "não-transparência" lexical que deve nortear o trabalho de seleção do vocabulário e de elaboração do dicionário. Seu pressuposto é de que os elementos lexicais de uma língua não demandam o mesmo esforço de aprendizagem devido ao fenômeno da dupla transparência: aquela interlinguística, resultante de associações morfossemânticas que podem ser feitas entre as línguas, e aquela resultante dos fenômenos de derivação ou de composição intralinguística que permitem que o aprendiz, tendo um conhecimento mínimo das regras morfológicas da LE, consiga depreender palavras derivadas. Para o autor, esse estudo começa pela escolha do(s) gênero(s) discursivo(s) como base para a seleção lexical, ambos devendo levar em conta principalmente o critério de pertinência pedagógica.

Afora as especificidades dos trabalhos que mencionamos - um destinado ao auxílio à leitura, outro, à aprendizagem de um vocabulário "passivo" -, podemos dizer que as reflexões por eles desenvolvidas se complementam e nos ajudam a distinguir algumas das particularidades de um dicionário destinado, direta ou indiretamente, à leitura em LE: para ambos os autores, esse dicionário deve partir de modificações de um DB, ou seja, constituir-se como um instrumento lexicográfico que traga informações sobre a LE na $L M$ do consulente; esse DB deve, por outro lado, passar por transformações tanto em sua macroestrutura como em sua microestrutura em razão das particularidades do escrito, mas também dos objetivos do consulente e de seu conhecimento da LE. 
LOGUERCIO, S. D. - Por um dicionário bilíngue pedagógico para a leitura em língua estrangeira

Se, além disso, levamos em conta as especificidades do aprendiz-leitor e as atuais condições do fazer lexicográfico, outras considerações devem ser acrescentadas. Em primeiro lugar, na era dos dicionários informatizados, nada parece justificar a economia de informações e a cisão de funções do dicionário, como, por exemplo, a função de decodificação vs a função de aprendizagem. Ainda mais na medida em que as dificuldades de leitura desse consulente estão relacionadas, em grande parte, com lacunas de aprendizagem relativas à gramática da LE, e não apenas com lacunas vocabulares. $O$ maior desafio, nesse sentido, seria então o de didatização do $\mathrm{DB}$, o que passa pela revisão de sua metalinguagem, de sua organização e pelo uso de expedientes diversificados para dar conta do semantismo das palavras e de seu funcionamento discursivo e gramatical.

Em segundo lugar, se admitimos que as palavras não requerem o mesmo esforço de aprendizagem, não nos parece que este seja um critério para a seleção do vocabulário de um DB destinado ao aprendiz-leitor. Sabemos que as associações lexicais tanto intra quanto interlinguísticas que podem ser feitas pelo leitor estão naturalmente na base dos procedimentos de inferência do sentido durante a compreensão. No entanto, por um lado, essas associações dependem também dos elementos contextuais (sintagma e texto) e da situação de comunicação (marcadas no gênero discursivo) e, por outro, tendem a ser particulares aos indivíduos, como nos mostram as pesquisas em intercompreensão. ${ }^{10}$ Ademais, ao excluir tais elementos lexicais, excluir-se-ia todo o resto que os acompanha (locuções, idiomatismos, fraseologias, etc.), inclusive a possibilidade de questionar o sentido, num dado contexto, de palavras "conhecidas" do leitor. Se há, portanto, critérios de seleção a serem levados em conta, estes devem partir da escolha do gênero discursivo pertinente ao aprendiz e orientados, ao menos inicialmente, por uma análise

\footnotetext{
${ }^{10}$ Um dos principais resultados das pesquisas de Carrasco e Masperi (2004) é que o efeito de transparência ou de opacidade do léxico é de natureza eminentemente dinâmica e subjetiva.
} 
LOGUERCIO, S. D. - Por um dicionário bilíngue pedagógico para a leitura em língua estrangeira

que leve em conta a distribuição do léxico em áreas diversas que contemplem a diversidade de interesses. ${ }^{11}$

\section{Por um dicionário bilíngue pedagógico francês-português para a leitura}

Um dicionário elaborado para fins pedagógicos não é certamente a garantia de uma leitura bem-sucedida, mas pode ser acima de tudo um instrumento de apoio didático tanto para o aprendiz, consulente privilegiado, quanto para o professor, que deve ajudá-lo a integrar o dicionário a suas práticas de leitura. Esse instrumento de apoio deve, em suma, poder acompanhá-los em suas atividades didáticas e de leitura e, sobretudo, estimular o aprendiz a aprofundar seu conhecimento da LE através do confronto com o escrito.

Um dos principais desafios, nesse sentido, é levar o aprendiz a desempenhar o papel de observador do emprego das formas linguísticas, e romper, de algum modo, com a crença - reforçada sem dúvida pelo uso do DB convencional - na equivalência das "palavras". A esse respeito, convém lembrar que:

Longe de serem nomenclaturas distintas, as línguas são acima de tudo redes de significação que o mundo experimentado organiza de diferentes maneiras. A língua não é constatação, mas delimitação de fronteiras dentro do experimentado. (SZENDE 1996: 112)

\footnotetext{
${ }^{11}$ Nesse sentido, o critério de seleção se oporia ao critério terminológico, preocupado com o uso especializado da língua.
} 
LOGUERCIO, S. D. - Por um dicionário bilíngue pedagógico para a leitura em língua estrangeira

Insistimos, assim, em alguns aspectos que nos parecem essenciais para a renovação dos dicionários utilizados pelos aprendizes em situação de leitura, tais como: a noção de unidade lexical, a construção da referência e, por fim, a observação do contexto. Esses aspectos servem, por um lado, de base para a organização do instrumento lexicográfico visado e, por outro, constituem em si mesmo saberes a serem adquiridos pelos aprendizes. Tais considerações repercutirão sobretudo na microestrutura do $D B$, onde se encontra boa parte do trabalho de didatização exigido por tal projeto e à qual restringimos nossas ilustrações. ${ }^{12}$

\subsection{A identificação da unidade lexical}

Um dos principais saberes a ser adquirido pelo aprendiz é a noção de "unidade lexical” (CRUSE 1987 apud BogaARds 1994) ou "lexia” (Pottier 1992), definida como uma palavra ou uma sequência de palavras - não se confundindo, portanto, com afixos e/ou morfemas - que constitui uma unidade semântica. Dito de outra maneira, trata-se de uma "sequência de palavras memorizada como signo individualizado" (POTTIER, op cit.: 34), podendo coincidir com a palavra gráfica, mas incluindo igualmente locuções, expressões idiomáticas e mesmo fraseologias. Com efeito, é pela assimilação das unidades lexicais, e não das palavras, que o aprendiz enriquecerá seu vocabulário e poderá identificar as unidades mínimas de significação dos textos, o que constitui um dos principais desafios no início da aprendizagem de uma LE e do processo de leitura, no qual todas as palavras parecem merecer o mesmo tipo de atenção.

Se a maioria dos dicionários toma a unidade lexical como sua unidade de descrição semântica privilegiada - o que é percebido, em princípio, nas

\footnotetext{
${ }^{12}$ As soluções propostas aqui são resultado igualmente da análise de 21 DBs (em formato impresso ou on-line) (Loguercio, 2013).
} 
LOGUERCIO, S. D. - Por um dicionário bilíngue pedagógico para a leitura em língua estrangeira

acepções de um verbete - isso nem sempre fica claro ao consulente. No caso específico dos DBs, além da marcação gráfica, vê-se essa tentativa através da separação homonímica (mais de uma entrada), da metalinguagem gramatical (indicação da classe gramatical e da transitividade verbal) e, em alguns casos, do recurso dos "discriminadores semânticos" (indicações de contexto). Se a primeira deve ser mantida com base em critérios semânticos e sintáticos, a segunda deve ser adaptada e o terceiro elemento, repensado, uma vez que pode se tornar um obstáculo de compreensão a mais para o consulente visado. $\mathrm{Na}$ verdade, os discriminadores na LE estabelecem relações de diferentes naturezas com a unidade lexical (hiperonímia, sinonímia, coocorrência, etc.), nem sempre evidentes para o aprendiz, além de restringir a aplicação referencial da unidade tratada.

Para distinguir as unidades lexicais, propomos então, além da clara disposição dos elementos no espaço e do acesso por etapas - através de links , uma reformulação do comentário sobre a forma, que deve ser adaptado ao aprendiz e levá-lo a se apoiar na observação da construção sintagmática da palavra para então aceder ao significado. Assim, ao buscar pela forma "croissant", ${ }^{13}$ por exemplo, que corresponde a várias lexias, o consulente teria acesso, num primeiro momento, às seguintes informações:

Quadro 1 - Dados para o acesso às lexias relacionadas à forma croissant

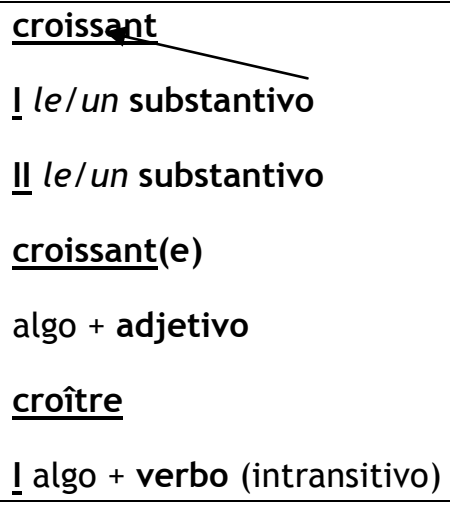

\footnotetext{
${ }^{13} \mathrm{~A}$ escolha das unidades ilustradas foi feita com base em pesquisa empírica realizada junto a alunos de FI, tendo sido tais unidades, num ou noutro momento, objeto de consulta por parte dos participantes (ver Loguercio, 2013).
} 
LOGUERCIO, S. D. - Por um dicionário bilíngue pedagógico para a leitura em língua estrangeira

II alguém/algo + verbo (intransitivo)

A nomenclatura gramatical viria marcada, a fim de facilitar seu reconhecimento, e integrada a um esquema sintagmático elementar conforme a natureza da unidade buscada e de sua distribuição textual sempre determinada pela análise de corpus e de outros materiais de referência. A partir desses dados, o consulente teria a opção de entrar por uma das formas resultantes do paradigma da palavra de busca ou acessar diretamente um dos verbetes pelos números romanos. Ao optar pela primeira forma elencada (assinalada pela seta), ele teria acesso ao seguinte quadro com informações relativas ao comentário semântico, podendo acessar ainda cada um desses verbetes e obter outros dados:

Quadro 2 - Primeiros dados definitórios para os substantivos relacionados à forma croissant

\section{croissant}

! le/un substantivo

1 uma das formas da lua, (quarto) crescente: meia-lua

2 qualquer coisa que adquira ou se assemelhe à forma da meia-lua

II le/un substantivo

"pãozinho" feito de massa folhada em forma de meia-lua: croissant

Tal procedimento, que busca explicitar a metalinguagem gramatical, nem sempre compreendida pelo aprendiz, seria ainda mais relevante no caso de unidades compostas por palavras gramaticais, como vemos nos números I e II a seguir na busca por "où": 
LOGUERCIO, S. D. - Por um dicionário bilíngue pedagógico para a leitura em língua estrangeira

Quadro 3 - Dados de acesso às lexias relacionadas à forma où

où

I Em perguntas diretas ou indiretas (advérbio interrogativo) Ver ADVÉRBIOS INTERROGATIVOS III Associando uma oração a um substantivo (pronome relativo) Ver PRONOMES RELATIVOS

III au moment où (locução conjuntiva de tempo) Ver CONJUNCCÕES DE TEMPO

$\underline{\text { IV }}$ d'où (locução conjuntiva de consequência) Ver ARTICULADORES DISCURSIVOS

$\underline{\text { V }}$ 'importe où (locução adverbial de lugar) Ver ADVÉRBIOS DE LUGAR

Nesse caso, além do acesso aos verbetes (inclusive relativos a locuções ${ }^{14}$ ), o dicionário remeteria às grandes categorias gramaticais, favorecendo a integração da unidade tomada isoladamente ao conjunto da categoria à qual pertence. Essas remissões gramaticais facilitariam o acesso a breves sínteses de gramática, sempre a partir de uma perspectiva contrastiva, às quais dificilmente esse tipo de consulente tem acesso. Pela remissão indicada, teríamos o seguinte quadro:

Quadro 4 - Síntese gramatical dos advérbios interrogativos

Os ADVÉRBIOS INTERROGATIVOS introduzem perguntas sobre:

Modo: Comment vas-tu? Como você está?

Lugar: Où allez-vous? Onde vocês vão? / D’où est-ce qu'elle vient ? De onde ela está vindo? / Par où passeras-tu? Por onde você passará?

Tempo: Quand reviendras-tu? Quando você volta?

Causa: Pourquoi dois-tu partir ? Por que você deve ir embora?

...

Ver também PRONOMES INTERROGATIVOS

Tal instrumento permitiria igualmente a pesquisa na direção inversa, ou seja, pelas grandes categorias gramaticais, inclusive facilitando a consulta de uma à outra quando pertinente. Ao integrar léxico e gramática para o aprendiz-leitor, muitas vezes não familiarizado com a metaliguagem gramatical, ele estaria suprindo uma grande lacuna dos tradicionais DBs, onde informações gramaticais são reduzidas normalmente a apêndices de tabelas de conjugação verbal, de pouca utilidade ao consulente visado.

\footnotetext{
${ }^{14}$ Por serem unidades lexicais, locuções e outros tipos de combinatórias relativamente fixas teriam o mesmo tratamento das unidades simples.
}

TradTerm, São Paulo, v. 26, Dezembro/2015, pp. 345-375

www.usp.br/tradterm

http://www.revistas.usp.br/tradterm/index 
LOGUERCIO, S. D. - Por um dicionário bilíngue pedagógico para a leitura em língua estrangeira

\subsection{A construção da referência}

Diferentemente dos dicionários ditos de língua, que privilegiam a construção da referência pela equação semântica que estabelecem entre a palavra-entrada e os enunciados definitórios, os DBs, como dissemos, têm por objetivo oferecer equivalentes tradutórios. Se esses dados podem ajudar em muitos casos na compreensão das lexias, tal recurso nem sempre é adequado ao leitor que não tem um conhecimento aprofundado da língua ou um conhecimento prévio da unidade lexical pesquisada. As lexias, nesse caso, por não serem tratadas semanticamente de maneira explícita - uma vez que os elementos que permitem sua conceitualização são apagados -, mas antes associadas a lexias na outra língua de modo direto aos olhos do consulente, exigem deduções linguístico-textuais e uma boa compreensão do entorno da unidade pesquisada.

Para auxiliar o aprendiz na construção da referência, propomos então dois procedimentos a serem privilegiados de modo geral: a explicitação semântica através de um enunciado definitório analítico breve na LM do consulente, que busque manter uma relação, sempre que possível, entre as acepções (lexias) de modo a evidenciar os deslizamentos de sentido sofridos pela língua; seguido da apresentação de mais de um equivalente por lexia. Tal combinação evitaria a associação direta entre as palavras das duas línguas e ampliaria as condições de aplicação referencial da unidade consultada, que só pode ser definida realmente quando reintegrada ao contexto discursivo. Além dos exemplos já apresentados no Quadro 2, teríamos verbetes como estes:

Quadro 5 - Primeiros dados definitórios para as lexias relacionadas à forma pâture

\section{pâture}

I la/une substantivo

1 lugar de vegetação rasteira para onde se leva o gado: pastagem

2 alimento de animais: pasto, capim, ração, porção de comida, quinhão... 
LOGUERCIO, S. D. - Por um dicionário bilíngue pedagógico para a leitura em língua estrangeira

II la/une substantivo

o que "alimenta" o pensamento, um sentimento, uma ação (boa ou má) etc. de uma pessoa: alimento, comida, isca, chamariz, sustento...

pâturer

animal + verbo [+ pasto] (intransitivo ou transitivo direto)

comer vegetação rasteira: pastar

Se nos concentramos nas formas nominais, observamos que a separação das unidades é levada ao extremo, tornando evidente ao usuário algumas características da palavra que ele procura. Trata-se, em primeiro lugar, de uma unidade que pode remeter a um referente "picturável" (I.1 e I.2) ou “não-picturável” (II), para usar os termos de Galisson (1979). Essa distinção, mesmo que possa ser mais ou menos recoberta pelos equivalentes normalmente propostos em português, tais como "pasto" ou "pastagem", permanece oculta ao consulente se não for explicitada. Recursos como as aspas presentes na definição do verbete II ajudam também a indicar a mudança de referência, mantendo ao mesmo tempo o elo de significação entre as unidades, e evitam o uso, muitas vezes controvertido, de indicações do tipo "figurado", "concreto", "abstrato", etc.

Tal procedimento informa, em segundo lugar, sobre os recursos linguísticos que a cultura de partida utiliza para expressar determinada ideia e, consequentemente, revela o modo como recorta o mundo experimentado ou, em outras palavras, sua visão de mundo. 0 que não ocorre pelo acesso direto à equivalência funcional normalmente proposta pelos DBs, que pode antes acarretar memorização sem, no entanto, compreensão nem acesso às particularidades da língua-cultura objeto da consulta.

A fim de tornar o DB ainda mais pedagógico, outros dados podem enriquecer os verbetes, ampliando as possibilidades de compreensão e retenção da unidade lexical, tais como: o comentário etimológico e/ou morfológico (atrativo para muitos aprendizes), a indicação de relações paradigmáticas (seja por sua relação semântica, seja por sua relação de 
LOGUERCIO, S. D. - Por um dicionário bilíngue pedagógico para a leitura em língua estrangeira

derivação) e elementos enciclopédicos e culturais. ${ }^{15}$ Se abrimos assim o verbete I citado no Quadro 5, poderíamos ter acesso a essas informações através de links (como indicam as setas no quadro abaixo) e remissões a outros verbetes:

Quadro 6 - Dados complementares ao comentário semântico do verbete pâture I

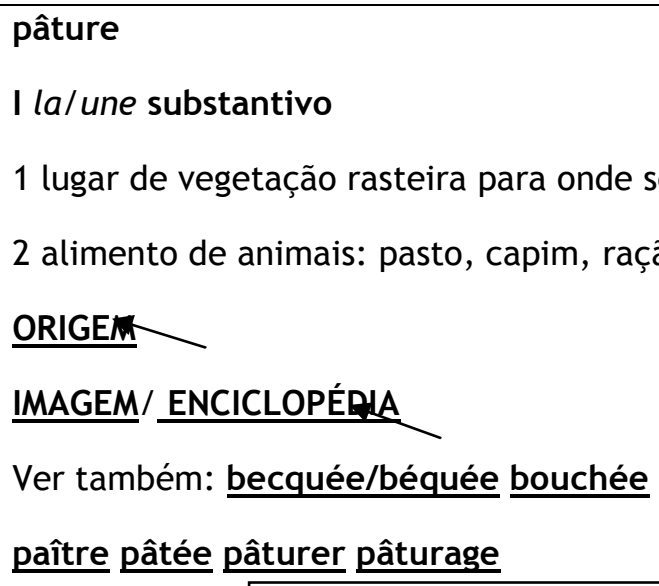

Do latim pastura, pascere (partícipio pastus) que originou o verbo paître em francês, levar ao pasto.

Sabemos que esse tratamento não seria, por outro lado, aplicável a todo tipo de unidade lexical. Unidades gramaticais, por exemplo, exigem um modo instrucional de definição para a construção da referência, isto é, uma definição que guie o leitor, através de uma descrição sintático-semântica, para a compreensão de seu funcionamento linguístico. Essa informação não pode se restringir tampouco, como vemos na maioria dos DBs, à indicação de equivalentes que "instruem" muito pouco o aprendiz; ou então contar com explicações destinadas à expressão, ao emprego da palavra, e não à

\footnotetext{
${ }^{15}$ Sendo o dicionário disponibilizado na web, um aproveitamento máximo poderia ser feito de outros recursos através de remissões para o google imagens, a wikipedia e mesmo outros dicionários e/ou banco de dados.
} 
LOGUERCIO, S. D. - Por um dicionário bilíngue pedagógico para a leitura em língua estrangeira

compreensão-leitora. Se retomamos o exemplo de "où" mencionado anteriormente, teríamos o seguinte quadro:

Quadro 7 - Dados definitórios para lexias relacionadas à forma où

\section{où}

I Em perguntas diretas ou indiretas (advérbio interrogativo) Ver ADVÉRBIOS INTERROGATIVOS questiona sobre o lugar de algo/alguém, de uma situação ou de uma ação: onde? aonde? por onde?..

II Associando uma oração a um substantivo (pronome relativo) Ver PRONOMES RELATIVOS

retoma uma informação de lugar ou de tempo para a construção que o sucede: onde (lugar), em que (tempo), por onde, de onde, no qual...

As definições propostas no Quadro 7, aproximando-se de formulações espontâneas, visam dar conta da função da unidade no enunciado e, tal como nos outros verbetes, vêm seguidas de equivalentes que buscam abranger construções possíveis em português a partir da análise de suas ocorrências em corpus. A compreensão efetiva da unidade tratada só se completará, todavia, pela leitura dos exemplos, que se tornam ainda mais essenciais nesses casos e, particularmente, para todas as unidades lexicais cuja descrição depende da relação que estabelecem com seus actantes semânticos (ou argumentos). ${ }^{16}$

\subsection{A observação do contexto}

É pela apresentação de alguns aspectos relativos ao contexto que um dicionário destinado à leitura-compreensão para o aprendiz pode melhor intervir em sua relação com o escrito, servindo finalmente de suporte para a compreensão em LE. Em tal projeto, consideramos dois tipos de contexto: aquele delimitado pelo gênero textual e, secundariamente, pela temática

\footnotetext{
${ }^{16}$ Esse conceito está na base da teoria Sentido-Texto na qual se distinguem as unidades de tipo "predicado semântico", "predicado quase-semântico" (ambas de sentido "liant") e "nomes semânticos" (entidades que podem ser definidas por meio de seus elementos internos). Ver Mel'cuk et al. (1995) e Polguère, (2008).
} 
LOGUERCIO, S. D. - Por um dicionário bilíngue pedagógico para a leitura em língua estrangeira

quando da constituição de um corpus (ou de corpora) que servirá de base para a coleta e a análise das unidades lexicais; e aquele constituído pelos elementos de um contexto próximo (ou cotexto) e que deve integrar o programa microestrutural do dicionário.

Quanto ao primeiro, normalmente desconhecido do consulente de DBs, ele serve, acima de tudo, para indicar as limitações de aplicação do programa dicionarístico. Quanto ao segundo, além de fornecer as informações linguísticas para a identificação das unidades lexicais, serve de base para a formulação dos exemplos e suas respectivas traduções. Os exemplos, bastante apreciados pelos aprendizes, oferecem a vantagem de explicitar as relações de coocorrência das lexias, criando uma ponte entre o abstrato da língua e o concreto do discurso e sustentam a compreensão dos equivalentes propostos em LM. Mais do que isso, eles enriquecem as relações associativas que estruturam nosso léxico mental à maneira do que ocorre quando estamos em situação de "recepção" durante a interação verbal, além de mostrar a palavra com as modificações morfológicas que pode sofrer quando integrada à construção sintagmática. Para isso, no entanto, diferentemente do que encontramos na maioria dos DBs, eles devem ser representativos do escrito e ilustrar o uso da língua que pode suscitar maior interesse por parte do aprendiz-leitor.

Compreendemos assim que, por um lado, esses dados não devem ser "fabricados", e sim privilegiar as construções mais prototípicas das unidades. Sugerimos proceder então, em um primeiro momento, a uma seleção de cotextos com base em um tratamento automático da linguagem (critério linguístico). Por outro lado, propomos haver, em um segundo momento, intervenção nessas construções a fim de que os exemplos extraídos do corpus sejam compreensíveis e significativos para o aprendiz (critério pedagógico). Estes viriam acompanhados de traduções na LM do consulente e seguidos pela possibilidade de consulta direta ao corpus do dicionário, de modo que 0 consulente teria dois tipos de informação ilustrativa do emprego da unidade 
LOGUERCIO, S. D. - Por um dicionário bilíngue pedagógico para a leitura em língua estrangeira

lexical: o exemplo que acompanha os elementos definitórios das unidades, preparado ad hoc a partir da extração do corpus, e as ocorrências da unidade lexical acessadas pelo corpus.

Para ilustrar esse procedimento, utilizamos o corpus preparado e disponibilizado gratuitamente na internet pelo Grupo de Pesquisa em Lexicografia Pedagógica (GRELEP), responsável pela Base lexicale du français (BLF). Esse corpus tem a vantagem de reunir textos jornalísticos, o que parece ser adequado a nosso público-alvo e ao que pretendemos mostrar.

Retomando a ilustração parcial das unidades relacionadas à forma “où", teríamos então os seguintes dados a partir do corpus:

Corpus Le Monde 1998 - exemples

Les exemples sont extraits automatiquement. Aucun contrôle n'a été effectué et il se peut donc qu'ils contiennent des erreurs.

20 occurrences pour où ${ }^{17}$. Affichage limité à 1000 occurrences.

\# 2 \# Premièrement, les capitaux reviennent se placer en lieu sûr sans qu'on ait besoin de les y inciter, d'où la perpétuation de faibles taux d'intérêt en Europe (et aux Etats -Unis).

\# 4 \# Lui objecte-t-on que cela fait rêver, notamment aux Etats -Unis, où le vétéran John Glenn, à soixante-dix-sept ans, repart pour un petit tour en orbite.

\# 5 \# Le jour où on verra que l'on peut sauver des vies grâce à la télémédecine, alors là, oui, le progrès sera visible.

\# 6 \# Comme j'ai à choisir où je mets l'argent, je préfère le mettre là.

\# 8 \# Jusqu'où la micro-informatique pourra-t-elle prolonger fuite en avant ?

\# 17 \# Avec une remarquable constance, les sondages révèlent depuis le début de la crise que l'on peut situer au moment où les grands médias ont commencé à évoquer l'affaire Monica Lewinsky, ...

\# 18 \# Sa côte de popularité, très haute au moment où l'affaire a éclaté, n'a que peu souffert les premiers jours et a même battu de nouveaux records au lendemain du discours sur l'état de l'Union,...

\# 20 \# Chez IDC, où l'on prend en compte à la fois les achats des entreprises et ceux des particuliers mais pas les dépenses de personnel des entreprises, M.Ochs évalue à environ $9 \mathrm{pc}$ la croissance :...

http://ilt.kuleuven.be/blf/exxxx_corpus.php?woord1=0\%25F9\&limiet=20

\footnotetext{
${ }^{17}$ Não vemos as 20 ocorrências buscadas na base originalmente, porque eliminamos a forma "ou" (conjunção) não distinguida na busca automática da forma "où" (pronome relativo e advérbio) que nos interessa aqui.
}

TradTerm, São Paulo, v. 26, Dezembro/2015, pp. 345-375

www.usp.br/tradterm

http://www.revistas.usp.br/tradterm/index 
LOGUERCIO, S. D. - Por um dicionário bilíngue pedagógico para a leitura em língua estrangeira

Nem todos os enunciados tomados em sua forma original são de grande utilidade para o aprendiz visado, pois proveem de contextos muito particulares e fazem referência a uma realidade imediata que é, normalmente, afastada da sua; ou ao contrário, podem, em alguns casos, não serem suficientemente ricos em elementos referenciais para servir de base para uma representação conceitual. No entanto, esses enunciados podem inspirar a (re)formulação dos exemplos, tanto no que diz respeito à sua construção sintática quanto no que diz respeito à escolha dos coocorrentes.

Para exemplificar o advérbio interrogativo, apoiamo-nos no cotexto (\# 8 \#); os exemplos do pronome relativo podem ser tirados dos cotextos (\# 4 \# e \# 5 \#); além das duas locuções conjuntivas que aparecem nessa amostra, "d'où" (\# 2 \#) e "au moment où" (\# 7 \# e \# 18 \#). Com base nesses enunciados, formulamos os seguintes exemplos para cada lexia:

Quadro 8 - Exemplo do advérbio interrogativo où

où I Em perguntas diretas ou indiretas (advérbio interrogativo) Ver ADVÉRBIOS INTERROGATIVOS questiona sobre o lugar de algo/alguém, de uma situação ou de uma ação: onde? aonde? por onde?...

Ex.: Jusqu'où la micro-informatique pourra-t-elle prolonger fuite en avant? (Até onde a micro-informática poderá prolongar essa corrida evolutiva?

Ver outros exemplos no CORPUS

Nesse caso, não foi preciso reformulação do enunciado. É interessante observar nessa ilustração que o advérbio pode vir antecedido por preposições que não foram previstas na lista de equivalentes, de modo que uma informação enriqueça a outra.

Quadro 9 - Exemplos do pronome relativo où

\footnotetext{
où

II Associando uma oração a um substantivo (pronome relativo) Ver PRONOMES RELATIVOS retoma uma informação de lugar ou de tempo para a construção que o sucede: onde (lugar), em que (tempo), por onde, de onde, no qual...

Ex.: Ce voyage fait rêver, notamment aux Etats-Unis, où un vétéran repart pour un tour en orbite. (Essa viagem faz sonhar, especialmente nos Estados Unidos, onde um veterano parte para uma volta no espaço.)
} 
LOGUERCIO, S. D. - Por um dicionário bilíngue pedagógico para a leitura em língua estrangeira

Ex.: Le jour où on verra que l'on peut sauver des vies grâce à la télémédecine, alors là le progrès sera visible. (No dia em que percebermos que podemos salvar vidas graças à telemedicina, então o progresso será visível.)

Nesse segundo caso, vemos que o primeiro exemplo passou por uma adaptação (omissão de dêiticos, de nomes próprios, etc., por um lado, substituição de algumas informações, por outro) a fim de que pudesse dispensar um contexto mais amplo. 0 interesse dos dois exemplos, de todo modo, está no contraste que eles ajudam a construir, marcando a polissemia da unidade. E está também, sobretudo no segundo exemplo, no contraste entre as construções em francês e em português.

Quadro 10 - Exemplos de locuções relacionadas à forma où

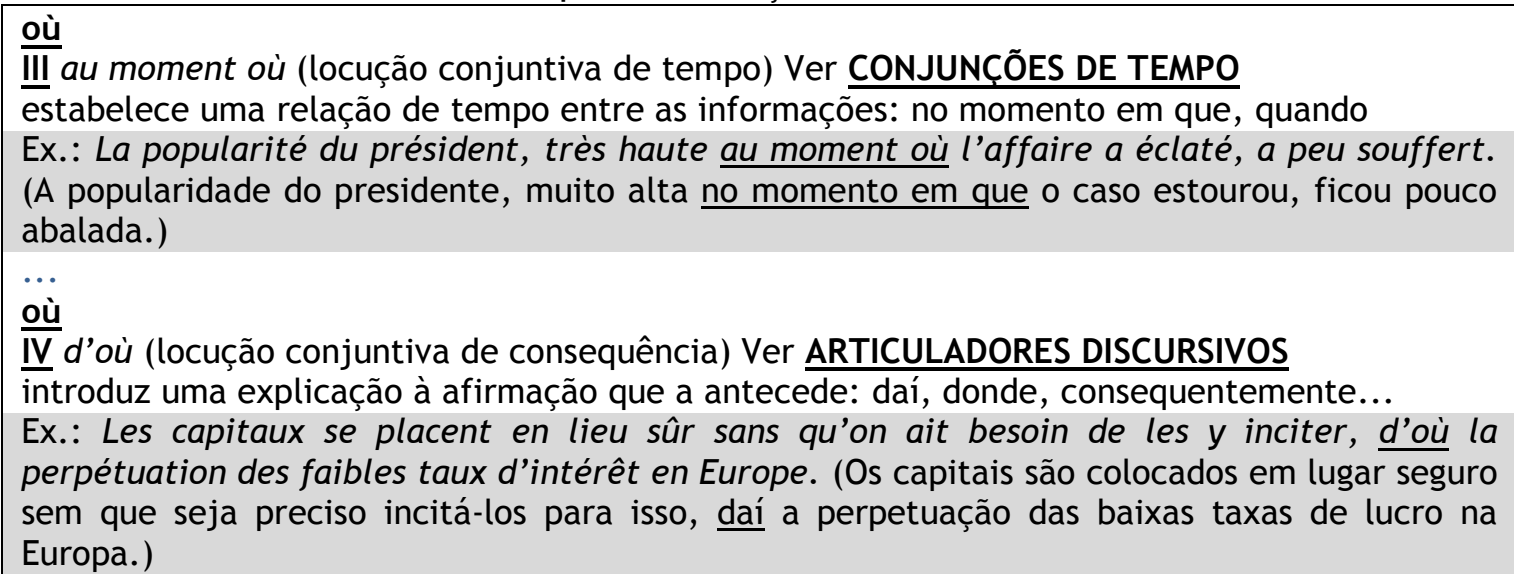

Os verbetes dedicados a locuções reforçam a noção de unidade lexical para o aprendiz; os exemplos, por sua vez, criam a possibilidade de confirmar essa noção, ainda mais na medida em que o consulente pode testar outras equivalências propostas na LM nos enunciados e tirar suas próprias conclusões.

A ilustração a seguir de lexias ligadas ao verbo rejoindre em sua forma transitiva direta nos possibilita observar outras vantagens da exemplificação por meio da aplicação dos mesmos procedimentos, tais como: a ilustração dos actantes semânticos, apenas sugeridos inicialmente, e a identificação das transformações morfológicas da unidade lexical. 
LOGUERCIO, S. D. - Por um dicionário bilíngue pedagógico para a leitura em língua estrangeira

\section{Quadro 11 - Exemplos relativos ao verbo rejoindre}

\section{rejoindre}

I alguém/algo + verbo + alguém/algo/lugar (transitivo direto)

1. ir ao encontro de um grupo, de uma pessoa ou de um lugar: (voltar a) fazer parte, integrar; juntar-se; voltar para; retomar...

Ex.: J'admire cette anthropologue qui a rejoint des militants politiques dans la lutte contre la torture et la pauvreté. (Admiro essa antropóloga que se juntou a militantes políticos para lutar contra a tortura e a pobreza.)

Ex.: Après avoir obtenu son diplôme d'études politiques, le jeune rejoint l'Unesco, l'organisation dont il partage les idéaux. (Depois de obter o diploma em estudos políticos, o jovem entra para a Unesco, a organização com a qual compartilha os ideais.)

2. entrar em contato com algo: atingir, alcançar, tocar..

Ex.: L'objectif est d'augmenter la production annuelle de $30 \%$ en rejoignant ainsi son concurrent. ( 0 objetivo é aumentar a produção anual em 30\%, alcançando assim 0 concorrente)

3. ter semelhança, pontos em comum: assemelhar-se, aproximar-se, coincidir...

Ex.: Le parti appuie le gouvernement dans sa démarche de réforme, dont les principes rejoignent ce qui avait guidé ses réflexions. ( 0 partido apoia o governo em seu processo de reforma cujos princípios coincidem com o que tinha norteado suas reflexões)

A partir dessas breves ilustrações, vemos que o suporte de aprendizagem criado pelos exemplos (ou cotextos) seguidos de uma tradução está sobretudo nas relações que o consulente pode estabelecer entre os diversos dados que compõem o verbete. A apresentação do cotexto não se limita a confirmar o significado apenas sugerido pelos dados definitórios, mas alimenta, pela relação que estabelece com eles, saberes importantes para o aprendiz-leitor, tais como o de unidade lexical e o de função gramatical e discursiva. As traduções ocupam um lugar essencial nesse quadro, pois favorecem a comparação interlinguística e mostram a aproximação possível no caso dos exemplos, apoiada em uma equivalência funcional - que pode ser realizada entre os enunciados nas duas línguas. 
LOGUERCIO, S. D. - Por um dicionário bilíngue pedagógico para a leitura em língua estrangeira

\section{Considerações finais}

Como buscamos mostrar, a elaboração de um DB pedagógico destinado à leitura requer, por um lado, uma renovação do conteúdo lexicográfico e, por outro, uma flexibilização da própria arquitetura do dicionário (distribuição e apresentação da informação). Para tanto, quatro condições se revelam essenciais: i) a constituição e a preparação para o tratamento automático da linguagem de um corpus de textos escritos em língua francesa de grande circulação (textos jornalísticos organizados por temáticas e/ou subgêneros), a fim de responder às necessidades de um público de leitores heterogêneo; ii) a constituição de uma base de dados informatizada que preveja os diferentes dados lexicográficos aqui ilustrados e que possa ser alimentada regularmente e acrescida de novos corpora; iii) uma interface que facilite a consulta e possibilite o acesso aos dados de maneiras variadas, por palavras lematizadas ou não, por formas simples ou complexas, mas que possa também sugerir a busca ao aprendiz (através de uma lista de palavras); iv) e finalmente a disponibilização do dicionário na internet e remissões a outros recursos de consulta lexical já disponíveis na web e que vêm complementar os dados oferecidos.

Com efeito, uma das maneiras de reunir as funções comunicativa e cognitiva requeridas pela lexicografia pedagógica e úteis ao aprendiz-leitor parece estar na possibilidade de o consulente circular de uma informação à outra, como nos propicia o recurso hipertextual, de modo que a pesquisa lexical seja suficientemente rica e que, através dela, seja remetido de volta ao texto, à gramática e mesmo a dados enciclopédicos. Nesse percurso, talvez o leitor possa construir sua própria "glosa" para a palavra na LE que suscitou sua consulta; o dicionário o terá levado, de qualquer modo, muito além do que supunha obter através da equivalência lexical. 
LOGUERCIO, S. D. - Por um dicionário bilíngue pedagógico para a leitura em língua estrangeira

\section{Referências bibliográficas}

Alvar Ezquerra, M. La forme des dictionnaires à la lumière du signe linguistique. Cahiers de lexicologie, n. 52(1), pp. 117-130, 1981.

BEJOINT, $H$. The foreign student's use of monolingual English dictionaries: A study of language needs and reference skills. Applied Linguistics, n. 2(3), pp. 207-222, 1981.

. Vers un dictionnaire bilingue de médiation. In: SZENDE, Thomas (org.) Les écarts culturels dans les dictionnaires bilingues, Paris: Honoré Champion, 2003: 207-221.

- Dictionnaires anciens, dictionnaires nouveaux, représentation de la langue et du discours. Revue Française de Linguistique Générale, vol. X, n. 2, pp. 11-18, 2005.

BINON, J.; VERLINDE, S. Lexicographie pédagogique. Des principes théoriques à la pratique. Congrès Enseignement du lexique et des terminologies : corpus, stratégies et méthodes, Journées d'étude, Liège, v. 43, n. 22, pp. 87-100, 2008.

BogAARDS, P. A propos de l'usage du dictionnaire de langue étrangère. Cahiers de lexicologie, n. 52, pp. 131-152, 1988.

. Le vocabulaire dans l'apprentissage des langues étrangères.

Coll. Crédif, Paris: Didier, 1994.

- Dictionnaires et compréhension écrite. Cahiers de lexicologie, n. 67(2), pp. 37-53, 1995.

CARRASCO, E.; MASPERI, M. L'analyse contrastive au service de la didactique des langues romanes: propositions autour de l'axe lexico-sémantique". In: BOYER, Langues et contacts de langues dans l'aire méditerranée. Pratiques, Représentations, Gestion. Paris: L'Harmattan, 2004: 131-148.

CONTI, V.; GRIN, F. S'entendre entre langues voisines: vers l'intercompréhension. Genève : Médecine et Hygiène - Georg, 2008.

CARVAlHo, O. Lexicografia bilíngue português/alemão: teoria e aplicação à categoria das preposições. Brasília: Thesaurus, 2001.

Galisson, R. Lexicologie et enseignement des langues. Paris: Hachette, 1979. Des mots pour communiquer. Paris: CLE, 1983. 
LOGUERCIO, S. D. - Por um dicionário bilíngue pedagógico para a leitura em língua estrangeira

GAONAC'H, D. et al. Psycholinguistique textuelle. Paris: Armand Colin, 1996.

GRIGGS, P. et al. La dimension cognitive dans l'apprentissage des langues étrangères. Revues française de linguistique appliquée, n. 2, v. VII, pp. 25-38, 2002.

HAUSMANN, F. J. La transparence et l'obstacle. Essai de chrestolexicographie. Revue de didactologie des langues et cultures et de lexiculturologie, n. 128(4), pp. 447-454, 2002.

LAHIRE, B. La raison scolaire. École et pratiques d'écriture, entre savoir et pouvoir. Rennes: Presses Universitaires de Rennes, 2008.

Loguercio, S. D. O uso de dicionários bilíngues por alunos de Francês Instrumental. Horizontes de Linguística Aplicada, ano 6, n. ${ }^{\circ} 2$, pp. 199-219, 2007.

Dictionnaires bilingues et pédagogie de la lecture. Tese de doutorado em Ciências da Linguagem. Paris: Université de la Sorbonne Nouvelle, Paris 3, 2013.

Marello, C. Les différents types de dictionnaires bilingues. In: Bejoint, H. e THOIRON, P. Les dictionnaires bilingues. Louvain-la-Neuve: Duculot, 1996: 3152

MEL'CUK, I. et al. Introduction à la lexicologie explicative et combinatoire. Louvain-la-Neuve: Duculot, 1995.

Pietraroia, C. C. Percursos de Leitura. São Paulo: Annablume, 1997.

Polguere, A. Lexicologie et sémantique lexicale. Montréal: Presses de l'Université de Montréal, 2008.

POTTIER, B. Sémantique générale. Paris: PUF, 1992.

Spinelli, E.; Ferrand, L. Psychologie du langage. L'écrit et le parlé, du signal sonore à la signification. Paris: Armand Colin, 2005.

SZENDE, T. Problèmes d'équivalence dans les dictionnaires bilingues. In: BEJOINT, H.; THOIRON, P. Les dictionnaires bilingues. Louvain-la-Neuve: Duculot, 1996: 111-126.

TARP, S. Desafíos teóricos y prácticos de la lexicografía de aprendizaje. In: BEVILACQUA, C. et al.. Lexicografia pedagógica: pesquisas e perspectivas. Florianópolis: UFSC/NUT, 2008: 46-72. 
LOGUERCIO, S. D. - Por um dicionário bilíngue pedagógico para a leitura em língua estrangeira . The foundations of a theory of learners' dictionaries. In: WIEGAND, H. E. Lernerlexikographie in Europa. Stand und Perspektiven. Tübingen: Neymeier, 2009: 155-158.

TYVAERT, J.-E. (2008). Pour une refondation de la didactique des langues sur la base de l'intercompréhension. In: CONTI, V.; GRIN, F. S'entendre entre langues voisines : vers l'intercompréhension. Genève : Médecine et Hygiène - Georg, 2008: 251-276.

WELKER, H. A. Dicionários. Uma pequena introdução à lexicografia. Brasília: Thesaurus. 2005.

- O uso de dicionários. Panorama geral das pesquisas empíricas. Brasília: Thesaurus. 2006.

Thesaurus, 2008. - Panorama geral da lexicografia pedagógica. Brasília: 